estingly, neither infection nor clots have been reported to date in thoracic aortic endovascular stent grafts.

As this article presents our initial experience with autologous sequential transposition and stent-graft placement, no statements can currently be made about the long-term outcome of the procedure. Several technical aspects have to be considered. The formation of type 1 endoleaks in this highly shear-stress-exposed area must be closely monitored. Additionally, because of the very curved pathway in this anatomic location, a backbone fracture of the stent graft must be kept in mind. Nevertheless, combined approaches for arch aneurysms will extend the applicability of the procedure in this delicate anatomic region. In fact, a variety of adjunctive techniques of stent-graft placement in patients with arch aneurysms are currently available. ${ }^{8-11}$ These techniques will allow safe and effective treatment of this highly select subgroup of patients with aortic aneurysms by avoiding conventional arch aneurysm repair in deep hypothermia and circulatory arrest.

\section{References}

1. Kazui T, Washiyama N, Muhammad BA, Terada H, Yamashita K, Takinami M. Improved results of atherosclerotic arch aneurysm operations with a refined technique. J Thorac Cardiovasc Surg. 2001;121: 491-9.

2. Westaby S, Katsumata T. Proximal aortic perfusion for complex arch and descending aortic disease. J Thorac Cardiovasc Surg. 1998;115: 162-7.

3. Dake MD, Kato N, Mitchell RS, et al. Endovascular stent-graft place- ment for the treatment of acute aortic dissection. $N$ Engl $J$ Med. 1999;340:1546-52.

4. Nienaber CA, Fattori R, Lund G, et al. Nonsurgical reconstruction of thoracic aortic dissection by stent-graft placement. $N$ Engl J Med. 1999;340:1539-45.

5. Dake MD, Miller DC, Semba CP, Mitchell RS, Walker PJ, Liddell RP. Transluminal placement of endovascular stent-grafts for the treatment of descending thoracic aortic aneurysms. N Engl J Med. 1994;331: 1729-34.

6. Hutschala D, Fleck T, Czerny M, et al. Endoluminal stent-graft placement in patients with acute aortic dissection type B. Eur J Cardiothorac Surg. 2002;21:964-9.

7. Schoder M, Grabenwoger M, Holzenbein T, et al. Endovascular stentgraft repair of complicated penetrating atherosclerotic ulcers of the descending thoracic aorta. J Vasc Surg. 2002;36:720-6.

8. Criado FJ, Barnatan MF, Rizk Y, Clark NS, Wang C. Technical strategies to expand stent-graft applicability in the aortic arch and proximal descending thoracic aorta. J Endovasc Ther. 2002;9:II328.

9. Buth J, Penn O, Tielbeek A, Mersman M. Combined approach to stent-graft treatment of an aortic arch aneurysm. J Endovasc Surg. 1998;5:329-32.

10. Iguro Y, Arata K, Yamamoto H, Masuda H, Sakata R. A new concept in distal arch aneurysm repair with a stent graft. $J$ Thorac Cardiovasc Surg. 2002;123:378-80.

11. Okada K, Sueda T, Orihashi K, Watari M, Ishii O. An alternative procedure of endovascular stent-graft repair for distal arch aortic aneurysm involving arch vessels. J Thorac Cardiovasc Surg. 2001; 121:182-4.

12. Vogt PR, Brunner-La Rocca HP, Carrel T, et al. Cryopreserved vascular allograft in the treatment of major vascular infection: a comparison with conventional surgical techniques. J Thorac Cardiovasc Surg. 1998;116:965-72.

\title{
Controlled exsanguination during sternal reentry
}

\author{
Alejandro Aris, MD, PhD, Barcelona, Spain
}

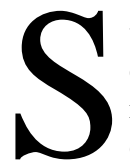

ternal reentry can cause catastrophic hemorrhage. Several maneuvers have been advocated to reduce this risk. $^{1-4}$ The new simple method of heart decompression during sternal reentry described here is based on controlled exsanguination ( $1500 \mathrm{~mL}$ of blood) through a long venous cannula before sternal opening, with rapid retransfusion through the same cannula. This technique avoids femoral artery cannulation.

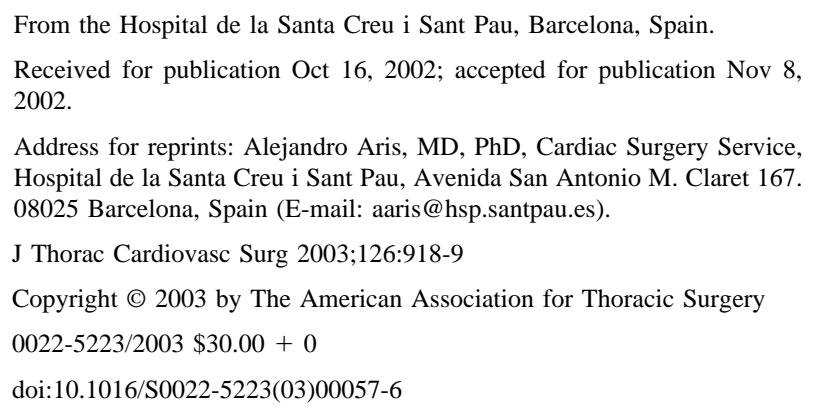

\section{Patients and Methods}

Patient data. Twelve patients underwent reoperation with this technique at my institution. All were subjected to valvular reoperations. Surgical procedures included 4 mitral

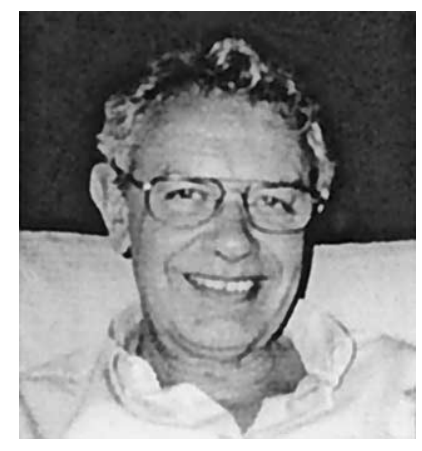

Alejandro Aris, MD, PhD valve replacements combined with tricuspid annuloplasty, 3 aortic valve replacements (2 with tricuspid annuloplasty), 1 tricuspid valve replacement, 2 repairs of a mitral periprosthetic leak, 1 mitral valve rereplacement because of pannus formation, and 1 double valve replacement for prosthetic endocarditis. It was the third operation for 1 patient and the fourth for another.

Surgical technique. After the skin was opened, the sternal wires were untwisted. The femoral vessels were exposed through a small groin incision. After complete heparinization, a long (50 cm) 28F cannula (DLP 96328; Medtronic, Inc, Minneapolis, Minn) was introduced into the vein by the Seldinger technique, and its tip was advanced up to the level of the right atrium. The cannula was connected to the venous line of the extracorporeal circuit and to the 

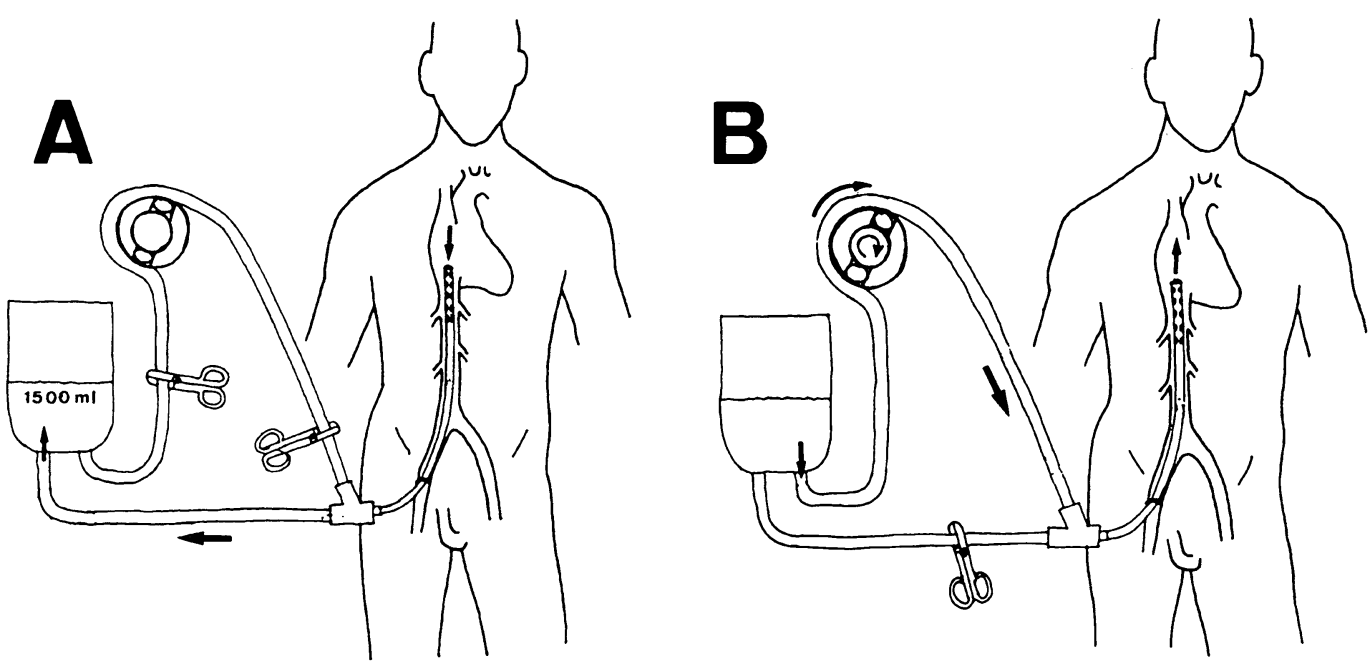

Figure 1. A, Blood $(1500 \mathrm{~mL})$ is removed through long cannula inserted in femoral vein before sternal opening. B, After sternum has been opened, blood is returned through arterial line, which has been connected to venous cannula.

arterial line through a side arm, which was initially clamped. After drainage of $1500 \mathrm{~mL}$ blood through the venous cannula (Figure 1, $A$ ), the wires were pulled upward and the sternum was opened with an oscillating saw. Once the sternum had been completely transected, the venous line was clamped and the same amount of blood was returned through the arterial line connected to the venous cannula (Figure 1, B). Hemodynamic stabilization was accomplished by further infusion of the oxygenator content as needed. Dissection of the right chambers was done after wire removal and placement of the sternal retractor. Standard cardiopulmonary bypass was instituted in the usual manner with a cannula in the ascending aorta connected to the arterial line. If opening of the right atrium was needed or the venous drainage was insufficient through the long cannula, a second venous cannula was placed in the superior vena cava. The surgical procedure was carried out in the standard fashion. After cardiopulmonary bypass had been discontinued, the femoral cannula was removed and the vein was repaired with a 5-0 polypropylene suture.

\section{Results}

There was no morbidity or mortality. There were no instances of cardiac chamber laceration. The sequence of systolic arterial pressure and times (mean \pm standard deviation) were as follows. From an initial $92 \pm 13 \mathrm{~mm} \mathrm{Hg}$, systolic pressure dropped to $32 \pm 23 \mathrm{~mm} \mathrm{Hg}$ after removal of $1500 \mathrm{~mL}$ blood, which was accomplished in $30 \pm 10$ seconds. The sternal saw was passed in $30 \pm 16$ seconds (range 15-60 seconds). Refilling with $1500 \mathrm{~mL}$ of the oxygenator content lasted 57 \pm 20 seconds and brought systolic pressure to $70 \pm 9 \mathrm{~mm} \mathrm{Hg}$ in 7 patients. In the remaining 5 patients, who had systolic pressures below $60 \mathrm{~mm} \mathrm{Hg}$ after refilling, further infusion of $500 \mathrm{~mL}$ increased systolic blood pressure to $75 \pm 11 \mathrm{~mm} \mathrm{Hg}$. The lowest systolic pressure during sternal opening was $21 \mathrm{~mm} \mathrm{Hg}$ for 20 seconds in 1 case.

\section{Discussion}

Catastrophic hemorrhage during sternal reentry is still a dreaded complication. Several techniques have been advocated to avoid laceration of the underlying cardiac structures during sternal reentry. ${ }^{1-4}$ Institution of partial cardiopulmonary bypass through the femoral vessels is another useful method. This enables sternal opening with a partially emptied heart and the possibility of retransfusion of blood should a cardiac laceration occur; however, cannulation of the femoral artery can be troublesome, either because of its small size or because of the presence of atheromatous plaques. The technique described here allows a fast emptying of the right heart chambers with rapid replenishment through the same venous cannula. Should persistent hemorrhage occur, institution of cardiopulmonary bypass can be done through the exposed femoral artery.

We have not encountered any cases of sustained hypotension, but this could be corrected with low doses of norepinephrine, especially in patients with coronary artery disease or aortic stenosis. In general, systolic blood pressure regains acceptable levels with the infusion of 1500 to $2000 \mathrm{~mL}$ of blood. The technique is simple and does not need any expensive equipment. Controlled exsanguination is a safe method of preventing uncontrolled, potentially lethal exsanguination during sternal reentry.

I am indebted to José Montiel, MD, for drawing the figure.

\section{References}

1. Dobell AR, Jain AK. Catastrophic hemorrhage during redo sternotomy. Ann Thorac Surg. 1984;37:273-8.

2. Akl BF, Pett SB, Wernly JA. Use of a sagittal oscillating saw for repeat sternotomy: a safer and simpler technique. Ann Thorac Surg. 1984;38: 646-7.

3. Grunwald RP. A technique for direct-vision sternal reentry. Ann Thorac Surg. 1985;40:521-2.

4. Gazzaniga AB, Palafox BA. Substernal thoracoscopic guidance during sternal reentry. Ann Thorac Surg. 2001;72:289-90. 